Journal of Animal and Veterinary Advances $10(8): 955-958,2011$

ISSN: $1680-5593$

(C) Medwell Journals, 2011

\title{
Feeding Responses to Central Glutamatergic Receptor Agonist Administrations in Meat-Type Chicks
}

\author{
${ }^{1,2}$ Takashi Bungo, ${ }^{1}$ Jun-Ichi Shiraishi and ${ }^{1}$ Shin-Ichi Kawakami \\ ${ }^{1}$ Department of Bioresource Science, Graduate School of Biosphere Science, \\ ${ }^{2}$ Japanese Avian Bioresource Project Research Center, \\ Hiroshima University, 739-8528 Higashi-Hiroshima, Japan
}

\begin{abstract}
The effects of Intra Cerebro Ventricular (ICV) injections of various glutamatergic receptor agonists were investigated using broiler chicks. ICV treatments with N-methyl-D-aspartate (NMDA: a selective agonist of NMDA-subtype of glutamatergic ionotropic receptors) stimulated feeding behavior of chicks in a dosedependent manner. On the other hand, ICV administration of kainate (a selective agonist of kainate-subtype of glutamatergic ionotropic receptors), AMPA (a selective agonist of AMPA-subtype of glutamatergic ionotropic receptors) or ACPD (a metabotropic glutamate agonist) did not affect feed intake in meat-type chicks. These findings indicated the involvement of glutamate as a chemical mediator in the regulation of feeding behavior in the meat-type chick, possibly acting on the central nervous system in this line through NMDA-sensitive glutamatergic receptor.
\end{abstract}

Key words: Central nervous system, chick, feed intake, glutamatergic system, injections, receptor

\section{INTRODUCTION}

Glutamate is the neurotransmitter occurring at most excitatory synapses in the mammalian brain (Brann, 1995; Pin and Duvoisin, 1995) which plays important roles in the formation of synapses and neuronal circuitry, long-term potentiation and depression and both normal learning and addictive behavior (Pelligrini-Giampetro et al., 1997; Wickelgren, 1998). Furthermore, glutamate was demonstrated to be an endogenous agent involved in the neural control of feed intake and body weight. Systemic, Intra Cerebro Ventricular (ICV) or local administration of glutamate can evoke a dose-related stimulation of feed intake in mammals (Reddy et al., 1986; Ritter and Stone, 1987; Wandji et al., 1989; Stricker-Krongrad et al., 1992; Stanley et al., 1993b). The action of glutamate is mediated by three distinct ionotropic receptor families, namely kainate, $\quad \alpha$-amino-3-hydroxy-5-methyl-4isoxazoleproprionate (AMPA) and N-methyl-D-aspartic acid (NMDA) receptors and by eight metabotropic receptors.

The hyperphagic effect of glutamate appears to be mediated by NMDA as well as by other excitatory amino acid receptor subtypes in mammals (Stanley et al., 1993a). Similar to mammalian systems, glutamate receptors are widely distributed in the avian central nervous system (Henley et al., 1989; Ottiger et al., 1995) and can be involved in learning and memory processes as well as in neuroendocrine control mechanisms (Jacquet et al., 1994; Riters and Bingman, 1994; Gruss and Braun, 1996). While the involvement of central glutamatergic mechanisms in the control of avian feeding behavior has been recently suggested, there are conflicting reports concerning such effects of glutamate (Zeni et al., 2000; Bungo et al., 2002; Da Silva et al., 2003; Zendehdel et al., 2009).

The aim of this present series of experiments was to examine the acute effect of central injection of various glutamate agonists on the feeding behavior in meat-type chicks.

\section{MATERIALS AND METHODS}

Day-old male broiler chicks (Cobb) were purchased from a local hatchery (Fresh feeds, Ehime, Japan). The birds were maintained in a room with $24 \mathrm{~h}$ lighting and at a temperature of $30^{\circ} \mathrm{C}$. They were given free access to a commercial starter diet (Nihon Nosan Kogyo Co. Ltd., Yokohama, Japan) and water during the pre-experimental period. The chicks were maintained in accordance with the recommendations of the NRC (1985). They were distributed into experimental groups based on their body weight so that the average body weight was as uniform as possible for each treatment. The birds were reared individually in experimental cages and had

Corresponding Author: T. Bungo, Laboratory of Animal Behavior and Physiology, Department of Bioresource Science, Graduate School of Biosphere Science, Hiroshima University, 739-8528 Higashi-Hiroshima, Japan 


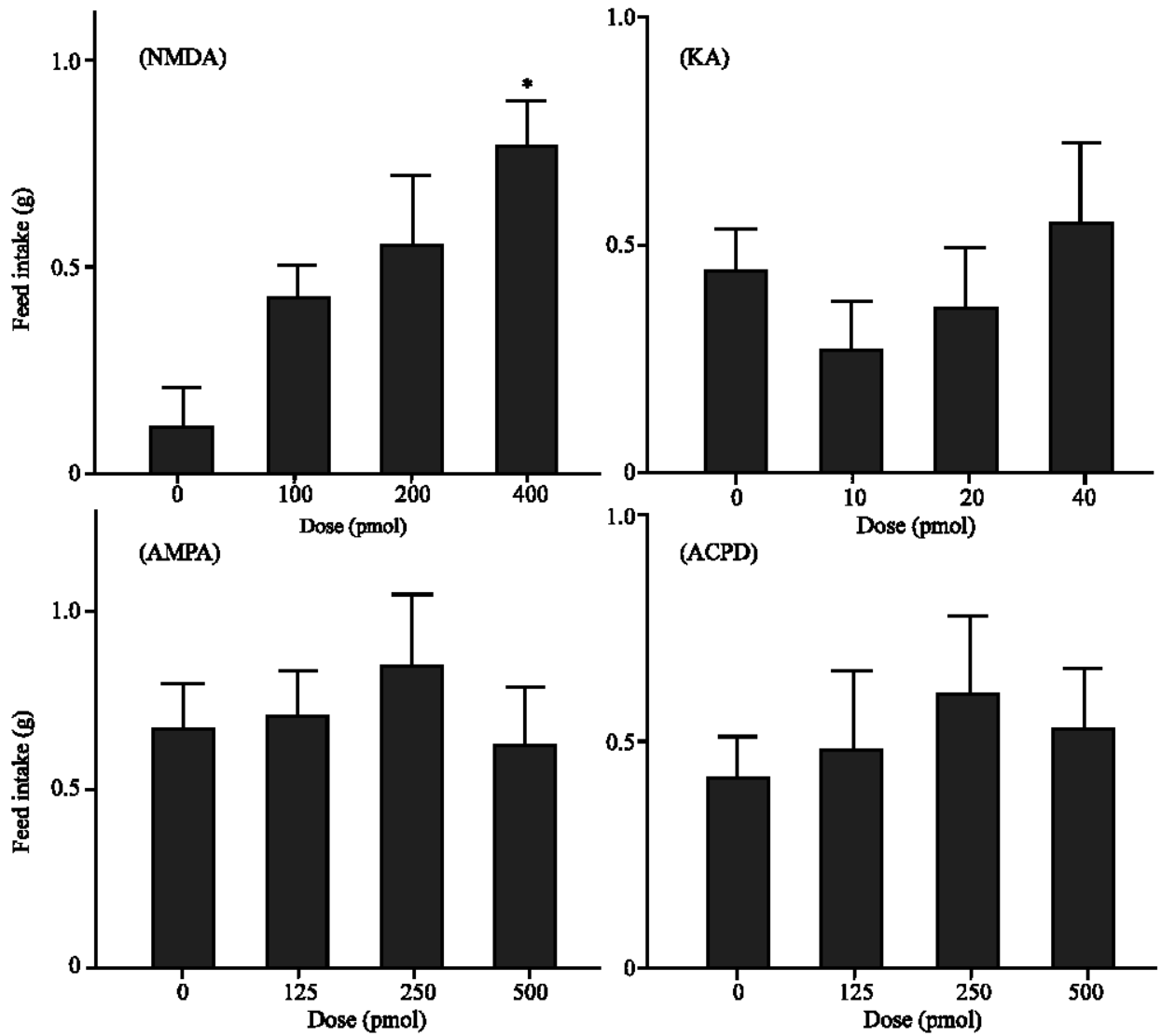

Fig. 1: Effects of intracerebroventricular injections $(10 \mu \mathrm{L})$ of the glutamatergic receptor agonists NMDA, KA, AMPA and ACPD on feed intake in ad libitum chicks. The number of chicks in each group was as follows: (NMDA) control, 6; 100 pmol, 6; 200 pmol, 5; 400 pmol, 5; (KA) control, 8; 10 pmol, 6; 20 pmol, 7; 40 pmol, 9; (AMPA) control, 8; 125 pmol, 7; 250 pmol, 6; 500 pmol, 7; (ACPD) control, 9; 125 pmol, 8; 250 pmol, 6; 500 pmol, 7. Data are expressed as means \pm SEM. ${ }^{*} \mathrm{p}<0.05$ (Turkey-Kramer test) compared to control chicks

ad libitum access to feed up to the time of experiments. Birds ( 2 or 3 days old) fed ad libitum were given diet for $30 \mathrm{~min}$ immediately after treatment. Feed intake was determined by measuring the reduction of diet from a pre-weighed feeder.

The weight of feeders was measured using an electric digital balance of precision $\pm 1 \mathrm{mg}$. N-methyl-Daspartate (NMDA), Kainate (KA), $\alpha$-amino-3-hydroxy-5methyl- 4-isoxazolepropionic acid (AMPA) and $( \pm)-1$ Aminocyclopentane-trans-1, 3-dicarboxylic acid (ACPD) were purchased from Sigma (St. Louis, MO, USA). The drugs were dissolved in a $0.1 \%$ Evans blue solution which was prepared in $0.85 \%$ saline. Saline containing Evans blue was used as a control. The birds were Intra Cerebro Ventricularly (ICV) injected with the solutions $(10 \mu \mathrm{L})$ using a microsyringe according to the methods used by Davis et al. (1979). Each chick was injected once only with saline or drug solution. The doses of agonists applied here were decided according to the preliminary trials that ascertained these doses of drugs had no effect on abnormal behavior (such as depression) in ad libitum chicks. At the end of the experiments, birds were sacrificed by decapitation after which the location of the injection site was confirmed. Data from the individuals that were not verified by the presence of Evans blue dye in the lateral ventricle were deleted. The numbers of birds used for data analysis are shown in Fig. 1. ANOVA was used to determine overall statistical significance due to treatment. When a treatment effect was significant, the Turkey-Kramer test was used to compare the significance among means. Statistical significance was set at $\mathrm{p}<0.05$. Data were expressed as means \pm SEM.

\section{RESULTS AND DISCUSSION}

Figure 1 shows the effects of ICV injection of glutamatergic receptor agonists (NMDA, KA, AMPA and $\mathrm{ACPD}$ ) on feed intake at $30 \mathrm{~min}$ after the injection. The 
ICV injection of NMDA (100-400 pmol) caused a dosedependent increase of feed intake in ad libitum broiler chicks $(F[3,18]=5.996, p<0.01)$. The higher level of NMDA (400 pmol) significantly induced feeding behavior $(\mathrm{p}<0.05)$. However all levels of KA $(10-40 \mathrm{pmol})$, AMPA (125-500 pmol) or ACPD (125-500 pmol) failed to affect feeding behavior in the ad libitum meat-type chicks when compared with control treatment $(\mathrm{p}>0.1)$.

The results on the orexigenic effect of NMDA are in accordance with findings seen in rats (Stanley et al., 1993a). However in the same report, AMPA and KA also induced a drastic increase in feed intake of rats. The reason for the difference between rats and chicks is unclear. There is a hypothesis that the method (ICV injection) used in this study would influence other sites of the brain and that it is possible the stimulated sites may attenuate the orexigenic effect of AMPK or KA. Bungo et al. (2002) found that central glutamate elicits feeding and the present study showed that ICV administration of NMDA but not AMPA, KA and metabotropic glutamatergic receptor agonists, induces hyperphagia in broiler chicks (Fig. 1). These results collectively suggest that the orexigenic effect of glutamate in chicks may be mediated through the NMDA receptor in the central nervous system.

The present findings contrast with those obtained in pigeons indicating that glutamate or glutamatergic receptor agonist (NMDA or AMPA) injections can inhibit feeding (Zeni et al., 2000). Similar to the pigeon study, central glutamate has an anorexic effect in 5 weeks old broilers (Zendehdel et al., 2009). They indicated a possible explanation that the differential effects of glutamatergic receptor agonists in rats and birds might be due to species properties (Zendehdel et al., 2009). However, the same explanation may not apply to the results using neonatal chicks (Bungo et al., 2002) (Fig. 1). Discrepancy in the glutamatergic receptor agonist response among the reports in avians supports the hypothesis that the role of central glutamatergic circuits in the control of feeding behavior may alter with age. Further, research is needed to clarify the age related changes of neuronal circuits in chickens.

A recent study using mammals has provided evidence for a glutamatergic phenotype of neurons in the arcuate nucleus, a key site for the regulation of feeding in the central nervous system (Meister, 2007). The arcuate nucleus contains two neuronal populations (Neuropeptide Y (NPY)/agouti-related protein and pro-opiomelanocortin (POMC)/cocaine and amphetamineregulated transcript) which integrate signals of nutritional status and influence energy homeostasis (Cone et al., 2001). Kiss et al. (2005) provided the evidence for the existence of glutaminergic innervation of NPY and POMC of the arcuate nucleus. In addition, considerable evidence has accumulated implicating glutamatergic system in the regulation of neuropeptide release (e.g., substance P: Caruso et al. (2006); orexin: Doane et al. (2007); melaninconcentrating hormone: Huang and van den Pol (2007)). Although, there is no report describing this relationship between glutamatergic system and these neuropeptides in chicks, it seemed that glutamate might modulate feed intake by excitatory effects on orexigenic and anorexigenic neurons of the arcuate nucleus in hypothalamus of chicks.

\section{CONCLUSION}

The present study suggests that central glutamate is involved in the central regulation of appetite via NMDAsensitive glutamatergic receptor in meat-type chicks. Elucidation of the molecular mechanism behind the interplay between hypothalamic glutamatergic and peptidergic neurons needs further investigation.

\section{ACKNOWLEDGEMENT}

The researchers are grateful to Dr. L. M. Liao for proofreading the manuscript.

\section{REFERENCES}

Brann, D.W., 1995. Glutamate: A major excitatory transmitter in neuroendocrine regulation. Neuroendocrinology, 61: 213-225.

Bungo, T., S. Yoshinaga and H. Ueda, 2002. Intracerebroventricularly administered excitatory amino acids: Effects on feeding behavior in chicks. J. Applied Anim. Res., 22: 161-168.

Caruso, C., D. Durand, H. Watanobe and M. Lasaga, 2006. NMDA and group I metabotropic glutamate receptors activation modulates substance $\mathrm{P}$ release from the arcuate nucleus and median eminence. Neurosci. Lett., 393: 60-64.

Cone, R.D., M.A. Cowley, A.A. Butler, W. Fan, D.L. Marks and M.J. Low, 2001. The arcuate nucleus as a conduit for diverse signals relevant to energy homeostasis. Int. J. Obes. Relat. Metab. Disord., 25: S63-S67.

Da Silva, A.A., J. Marino-Neto and M.A. Paschoalini, 2003. Feeding induced by microinjections of NMDA and AMPA-kainate receptor antagonists into ventral striatal and ventral pallidal areas of the pigeon. Brain Res., 966: 76-83. 
Davis, J.L., D.T. Masuoka, L.K. Gerbrandt and A. Cherkin, 1979. Autoradiographic distribution of L-proline in chicks after intracerebral injection. Physiol. Behav., 22: 693-695.

Doane, D.F., M.A. Lawson, J.R. Meade, C.M. Kotz and J.L. Beverly, 2007. Orexin-induced feeding requires NMDA receptor activation in the perifornical region of the lateral hypothalamus. Am. J. Physiol. Regul. Integr. Comp. Physiol., 293: R1022-R1026.

Gruss, M. and K. Braun, 1996. Stimulus-evoked increase of glutamate in the mediorostral neostriatum/ hyperstriatum ventrale of domestic chick after auditory filial imprinting: An in vivo microdialysis study. J. Neurochem., 66: 1167-1173.

Henley, J.M., R. Moratllo, S.P. Hunt and E.A. Barnard, 1989. Localization and quantitative autoradiography of glutamatergic ligand binding sites in chick brain. Eur. J. Neurosci., 1: 516-523.

Huang, H. and A.N. van den Pol, 2007. Rapid direct excitation and long-lasting enhancement of NMDA response by group I metabotropic glutamate receptor activation of hypothalamic melanin-concentration hormone neurons. J. Neurosci., 27: 11560-11572.

Jacquet, J.M., A. Robinson and M. Caldani, 1994. Release of chicken luteinising hormone-releasing hormone-I (cLHRH-I) by medio-basal hypothalamus in the cockerel: Validation of an incubation system and effect of excitatory amino-acids. Reprod. Nutr. Dev., 34: 185-191.

Kiss, J., Z. Csaba, A. Csaki and B. Halasz, 2005. Glutamatergic innervation of neuropeptide $\mathrm{Y}$ and proopiomelanocortin-containing neurons in the hypothalamic arcuate nucleus of the rat. Eur. J. Neurosci., 21: 2111-2119.

Meister, B., 2007. Neurotransmitters in key neurons of the hypothalamus that regulate feeding behavior and body weight. Physiol. Behav., 92: 263-271.

NRC, 1985. Guide for the Care and Use of Laboratory Animals. NIH Publication, Washington, DC.

Ottiger, H.P., A. Gerin-Moser, F. del Principe, F. Dutly and P. Streit, 1995. Molecular cloning and differential expression patterns of avian glutamate receptor mRNAs. J. Neurochem., 64: 2413-2426.

Pelligrini-Giampetro, D.E., J.A. Gorter, M.V.L. Bennett and R.S. Zukin, 1997. The GluR2 (GluR-B) hypothesis: $\mathrm{Ca} 2^{+}$-permeable AMPA receptors in neurological disorders. Trends Neurosci., 20: 464-470.
Pin, J.P. and R. Duvoisin, 1995. The metabotropic glutamate receptors: Structure and functions. Neuropharmacology, 34: 1-26.

Reddy, V.M., S.S. Meharg and S. Ritter, 1986. Doserelated stimulation of feeding by systemic injection of monosodium glutamate. Physiol. Behav., 38: 465-469.

Riters, L.V. and V.P. Bingman, 1994. The NMDA-receptor antagonist MK-801 impairs navigational learning in homing pigeons. Behav. Neural Biol., 62: 50-59.

Ritter, S. and S.L. Stone, 1987. Area postrema lesions block feeding induced by systemic injections of monosodium glutamate. Physiol. Behav., 41: 21-24.

Stanley, B.G., L.H. Ha, L.C. Spears and M.G. Dee, 1993a. Lateral hypothalamic injections of glutamate, kainic acid,d,1-á-amino-3-hydroxy-5-methyl-isoxazole propionic acid or N-methyl-d-aspartic acid rapidly elicit intense transient eating in rats. Brain Res., 613: 88-95.

Stanley, B.G., V.L. Willet, H.W. Donias, L.H. Ha and L.C. Spears, 1993b. The lateral hypothalamus: A primary site mediating excitatory amino-acid-elicited eating. Brain Res., 630: 41-49.

Stricker-Krongrad, A., B. Beck, J.P. Nicolas and C. Burlet, 1992. Central effects of monosodium glutamate on feeding behavior in adult Long-Evans rats. Pharmacol. Biochem. Behav., 43: 881-886.

Wandji, S.A., J.R. Seone, A.G. Roberge, L. Bedard and L. Thibault, 1989. Effects of intrahypothalamic injections of GABA, muscimol, pentobarbital and Lglutamic acid on feed intake of satiated sheep. Can. J. Physiol. Pharmacol., 67: 5-9.

Wickelgren, I., 1998. Teaching the brain to take drugs. Science, 280: 2045-2046.

Zendehdel, M., A. Baghbanzadeh, V. Babapour and J. Cheraghi, 2009. The effects of bicuculline and muscimol on glutamate-induced feeding behavior in broiler cockerels. J. Comp. Physiol. A: Neuroethol. Sensory Neural Behav. Physiol., 195: 715-720.

Zeni, L.A.Z.R., H.B.K. Seidler, N.A.S. de Carvalho, C.G. Freitas, J. Marino-Neto and M.A. Paschoalini, 2000. Glutamatergic control of food intake in pigeons: Effects of central injections of glutamate, NMDA and AMPA receptor agonists and antagonists. Pharmacol. Biochem. Behav., 65: 67-74. 